\title{
Cerebral haemodynamic changes after extracranial-intracranial bypass surgery
}

\author{
J M GIBBS, ${ }^{*} \dagger$ R J S WISE, ${ }^{*} \dagger$ D J THOMAS, $\ddagger$ A O MANSFIELD, $\S$ \\ R W ROSS RUSSELL†H
}

From the MRC Cyclotron Unit, Hammersmith Hospital,* The National Hospital for Nervous Diseases, $\dagger$ Department of Neurology, St Mary’s Hospital, $\ddagger$ Department of Vascular Surgery, St Mary’s Hospital, $\S$ and the Department of Neurology, St Thomas' Hospital, $\|$ London, UK

SUMMARY Regional cerebral blood flow, oxygen utilisation, fractional oxygen extraction, and cerebral blood volume were measured by positron emission tomography in twelve patients with carotid artery occlusion. Follow-up studies were carried out at a mean interval of eleven weeks after extracranial-intracranial bypass surgery. Clinical improvement was observed in three patients who had presented with frequent transient ischaemic attacks. One patient with multiple vascular occlusions suffered a stroke at the time of surgery. Follow-up studies showed an increase of regional cerebral blood flow in only two of the twelve patients. In the group as a whole, there was no significant change of cerebral blood flow, oxygen consumption or fractional oxygen extraction after bypass surgery. The most consistent post-operative change, observed in eleven of the twelve patients, was a fall of cerebral blood volume in the cortical territory of the bypassed carotid artery $(p<0.01)$. This effect was most marked in patients with bilateral carotid occlusion, in whom there was often an accompanying fall of blood volume in the contralateral hemisphere. The post-operative findings were consistent with an increase of regional cerebral perfusion pressure as a result of the bypass procedure. Although this effect is potentially of value, those patients with most to gain from bypass surgery may also run the highest risk of peri-operative cerebral ischaemia.

The role of surgery in the management of patients with cerebrovascular disease remains a controversial issue. Even carotid endarterectomy, which is now carried out more than 85,000 times a year in the USA, ${ }^{1}$ has yet to be shown by an adequate trial to reduce the risk of stroke in patients with carotid artery disease. ${ }^{2}$ Since the introduction of extracranial-intracranial (EC-IC) bypass surgery in the early $1970 \mathrm{~s},{ }^{34}$ the scope for surgical intervention has widened to include a large population of patients with inaccessible or otherwise inoperable lesions within the carotid arterial system. It is well established that occlusive carotid disease is associated with a substantial risk of stroke in the ipsilateral cerebral hemisphere, even in those patients who have survived a complete internal carotid occlusion with little or no neurological deficit. $^{5-13}$ The incidence of later cerebral infarction in such cases ranges from $2.5 \%$ to $8 \%$ per annum,

Address for reprint requests: Dr JM Gibbs, The National Hospital, Queen Square, London WCIN 3BG, UK.

Received 29 October 1985 and in revised form 9 May 1986. Accepted 15 May 1986 depending on the type of patient population selected for follow-up..$^{5-13}$ Furthermore, these delayed ischaemic events occur twice as often in the territory of the occluded vessel as in the contralateral hemisphere. ${ }^{101113}$ On theoretical grounds, surgical bypass of the obstructive lesion, by means of a superficial temporal to middle cerebral arterial anastomosis, could prevent the development of late cerebral infarction distal to an occluded carotid artery. The procedure is most likely to be of benefit when the patient's existing collateral circulation is inadequate to maintain normal cerebral perfusion, such that continuing ischaemic symptoms result from a haemodynamic mechanism rather than embolism. However, it has also been suggested that a protective effect against the ischaemic damage caused by emboli might be an important factor in some cases. ${ }^{14-16}$

Occasional anecdotal reports have described striking resolution of neurological deficits after EC-IC bypass surgery. ${ }^{17-19}$ However, many large clinical series have included no such cases, and it is generally accepted that the main purpose of the bypass procedure is to prevent further ischaemic events in a high 
risk population. ${ }^{1415}$ Whether it does so remains a matter of debate. Recent data from a centre with extensive experience of the procedure suggest that if anything, medically treated patients may do better than those undergoing bypass surgery. ${ }^{20}$ This impression was confirmed by the recently published results of the International EC-IC bypass Study, ${ }^{2122}$ which showed that the overall incidence of stroke was higher in patients subjected to bypass surgery than in the matched control population. Furthermore, amongst the patients in the surgical group who did particularly badly were those with continuing transient ischaemic attacks in the territory of a completely occluded carotid artery. Whilst this finding raises serious doubts about the value of the procedure, there may still be a small subgroup of patients with critically reduced cerebral perfusion pressure in whom surgical intervention should be considered. It is in this area of uncertainty that the findings of a large clinical trial may be complemented by the results of carefully conducted physiological studies in a relatively small number of patients.

Previous studies of cerebral blood flow before and after EC-IC bypass have produced disparate results. ${ }^{1623-32}$ Most investigators have observed only modest rises of blood flow in a minority of patients studied, the change being often a transient phenomenon which is no longer demonstrable 3 or 4 months after the procedure. ${ }^{272932}$ Some authors have suggested that a measurement of cerebral circulatory reserve, as judged by the capacity to increase blood flow in response to inhaled carbon dioxide, may be a more useful haemodynamic index than the level of blood flow itself. ${ }^{263133}$

More recent studies using positron emission tomography (PET) have enabled measurements to be made not only of cerebral blood flow, but also of the metabolic demands of the brain, as reflected by regional oxygen consumption. ${ }^{34}{ }^{35}$ It has been shown that there are some patients with occlusive carotid artery disease in whom cerebral blood flow is inappropriately low in relation to the oxygen requirements of surviving brain. ${ }^{16253637}$ This critical haemodynamic state is characterised by a compensatory rise of fractional oxygen extraction (normally less than $50 \%$ ), which maintains oxygen delivery to the tissues in the face of the reduced blood supply. A small number of patients have been reported in whom ECIC bypass surgery was followed by restoration of blood flow and a fall to normal levels of a previously raised oxygen extraction ratio. ${ }^{1625}$ Even when cerebral blood flow is still appropriately matched to metabolic demands, reduction of cerebral circulatory reserve may be evident as a regional increase of cerebral blood volume, consistent with focal vasodilatation in response to diminished cerebral per- fusion pressure. ${ }^{3637}$ Analysis of the relationship between blood flow, blood volume and oxygen extraction has suggested that the ratio of cerebral blood flow to blood volume (a reflection of mean flow velocity) provides a more sensitive index of cerebral perfusion pressure than either variable considered alone. ${ }^{3638}$

In view of the apparently minor and inconsistent effect of bypass surgery of cerebral blood flow, ${ }^{23-32}$ this study was carried out to establish whether other physiological variables, in particular the cerebral blood volume, might provide more information about the haemodynamic effect of the procedure.

\section{Methods}

\section{(1) Positron Emission Tomography}

Regional cerebral blood flow (CBF), oxygen extraction ratio (OER), oxygen utilisation $\left(\mathrm{CMRO}_{2}\right)$ and cerebral blood volume (CBV) were measured by positron emission tomography, using an ECAT II camera (EG \& G Ortec) with a spatial resolution of $16.7 \times 16.7 \times 16 \mathrm{~mm}$ at full width half maximum. ${ }^{34} 39$ By making measurements of regional radioisotope concentrations within a tomographic slice of tissue, positron tomography records and displays physiological data in a manner analogous to the reconstruction of an anatomical image by the conventional CT scanner. With simultaneous measurements of isotope activity in the arterial blood, physiological variables can be quantified in absolute units within any selected region of the brain. ${ }^{34} 35$ In this study, regional CBF and OER were measured by the oxygen15 steady-state technique, which has been described in detail elsewhere. ${ }^{34}$ Cerebral blood volume was measured by the carbon- 11 carboxyhaemoglobin technique. ${ }^{40}$ As well as providing physiological information in its own right, the blood volume measurement is used to correct for an overestimation of OER (and hence $\mathrm{CMRO}_{2}$ ) which otherwise occurs with the oxygen- 15 technique. ${ }^{41}$

The study procedure involves four successive tomographic scans of identical brain slices. Regional blood flow is derived from the cerebral isotope distribution during continuous inhalation of a tracer quantity of ${ }^{15} \mathrm{O}$-labelled carbon dioxide. ${ }^{34}$ The combined data from the $\mathrm{C}^{15} \mathrm{O}_{2}$ scan and a second scan during inhalation of ${ }^{15} \mathrm{O}$-labelled oxygen provide a measurement of the regional oxygen extraction ratio. Knowing also the total oxygen content of arterial blood $\left(\mathrm{O}_{2} \mathrm{C}\right)$, the rate of cerebral oxygen consumption $\left(\mathrm{CMRO}_{2}\right)$ can be calculated as the extracted fraction (OER) of the total amount of oxygen delivered to the brain per minute $\left(\mathrm{CBF} \times \mathrm{O}_{2} \mathrm{C}\right)$ :

$$
\mathrm{CMRO}_{2}=\mathrm{OER} \times \mathrm{CBF} \times \mathrm{O}_{2} \mathrm{C}
$$

The effect of tissue attenuation on the emission data is corrected regionally by means of a transmission scan through the appropriate brain slices, using an external germanium-68/gallium-68 ring source. ${ }^{34}$ Finally, the blood volume is measured by a fourth scan after labelling red cells with a tracer quantity of inhaled ${ }^{11} \mathrm{C}$-carbon monoxide. ${ }^{40}$ Serial arterial blood samples during the periods of steadystate inhalation of $\mathrm{C}^{15} \mathrm{O}_{2}$ and ${ }^{15} \mathrm{O}_{2}$ are taken by means of a fine gauge radial artery cannula.

The patients in this study were scanned through two tomographic planes, 4.5 and $6.5 \mathrm{~cm}$ above and parallel to the 




Cprtical regions $\quad 1.5 \times 9 \mathrm{~cm}$
Subcortical regions $2 \times 5 \mathrm{~cm}$

Fig 1 Schematic illustration of the "cortical" regions of analysis, in both tomographic planes, and the subcortical regions in the upper tomographic plane $(O M+4 \cdot 5=$ $4.5 \mathrm{~cm}$ above the orbito-meatal line).

orbito-meatal (OM) line, the primary area of interest being the territory of the middle cerebral artery. The patient's head position was closely monitored throughout each study by means of a light grid projected on to the forehead, the lines of which were kept aligned to markings made on the skin with a felt-tipped pen. For the follow-up studies, great care was taken to ensure that as far as possiöle, the patient was scanned through two anatomical planes identical to those in the pre-operative scan. The accuracy of repositioning was checked by a preliminary scan during the build-up period of $\mathrm{C}^{15} \mathrm{O}_{2}$ inhalation; any small discrepancies could then be corrected, by comparison with the pre-operative tomographic images, before the final measurements began.

Serial measurements in normal subjects studied on two occasions several weeks apart have shown mean variations of $16 \%$ in regional CBF, $12 \%$ in $\mathrm{CMRO}_{2}$ and $17 \%$ in OER. ${ }^{42}$ Changes in one or more of the three variables of between $30 \%$ and $40 \%$ were observed in a few individual cases. However, these studies were carried out using single arterial blood samples obtained by femoral arterial puncture, rather than serial samples from an indwelling arterial cannula. The results of the follow-up measurements reported in this study, particularly the $\mathrm{CMRO}_{2}$ values (see below), suggest that the degree of spontaneous variation in individual subjects was somewhat overestimated by the original technique using single arterial samples.

\section{(2) Data analysis}

Regional values of the four physiological variables were taken from two standardised regions of interest in each cerebral hemisphere. Firstly an objective technique of "cortical plotting" was used to delineate peripherally situated regions corresponding to the cortical distribution of the middle cerebral artery (MCA). ${ }^{3643}$ These regions, which were defined on both tomographic planes studied, are illustrated schematically in fig 1 . (Being $15 \mathrm{~mm}$ wide, these "cortical" strips are estimated to consist of approximately $55 \%$ grey matter
Gibbs, Wise, Thomas, Mansfield, Ross Russell and $45 \%$ white matter.) The values referred to below from cortical MCA territory represent the mean from these superficial regions in both tomographic planes studied in each patient.

The second type of region of interest, delineated by a standard programme on the ECAT computer, consisted of an oval area in the subcortical white matter on the higher $(\mathrm{OM}+6.5 \mathrm{~cm})$ tomographic brain slice. This region measured $5 \times 2 \mathrm{~cm}$ and its outer border was situated $2.5 \mathrm{~mm}$ deep to the inner border of the "cortical" region (see fig 1).

In one patient (case 5) an area of frankly infarcted brain (clearly demonstrated on both $x$-ray CT scan and PET images) was excluded from the quantitative analysis of the cortical region in the affected hemisphere. Pre- and postoperative values of the four physiological variables were considered separately for the MCA territory on the side of the operation and for the corresponding region in the contralateral hemisphere. All statistical comparisons were made by paired 2 -tailed $t$ test.

\section{Patients}

Twelve patients were studied before and after EC-IC bypass surgery on the side of a completely occluded internal carotid artery. Four patients had occlusion of both carotid arteries and in one of these (case 9), bilateral EC-IC bypass procedures were carried out. There were ten men and two women, ranging in age from 46 to 72 with a mean of $62 \pm$ 8 (SD). The clinical features, CT scan appearances and angiographic findings in each case are summarised in table 1. All patients had experienced recent cerebral symptoms (transient ischaemic attacks, minor stroke or both) consistent with ischaemia in the hemisphere ipsilateral to an occluded carotid artery. Many also had ocular symptoms. Seven of the twelve patients had at least one clinical feature to suggest a state of considerably reduced perfusion pressure distal to an occluded carotid artery. Three patients (cases 6,10 and 11) described hemispheric TIAs precipitated by sudden standing; two (cases 2 and 11) had experienced episodes of faintness or frank syncope, consistent with global cerebral ischaemia; two (cases 4 and 8 ) presented with very frequent TIAs, culminating in a persistent but fluctuating hemiparesis; and four patients (cases 4, 10,11 and 12) showed characteristic signs of low retinal perfusion pressure ${ }^{4445} \mathrm{In}$ two other patients (cases 5 and 9), the CT scan showed a watershed distribution of cerebral infarction, also favouring a haemodynamic (rather than embolic) basis for their cerebral ischaemic episodes.

The majority of patients were in a stable clinical state at the time of their pre-operative PET studies, having had no acute symptoms during the preceding few hours. Two, however (cases 4 and 8), could be described as being in a state of evolving cerebral ischaemia. Patient 4 was recovering from a minor stroke 5 days earlier but was still experiencing some fluctuation of the residual hemiparesis; patient 8 had developed persistent (but also fluctuating) hemiparesis and dysphasia only 6 hours prior to the PET study, having presented originally with increasingly frequent and prolonged TIAs in the same carotid territory. This latter patient therefore had acute, symptomatic cerebral ischaemia at the time of the study. Both of these patients with clinical features suggestive of critically low cerebral perfusion had complete bilateral 
Table 1 Summary of clinical and radiological findings in the twelve patients

\begin{tabular}{|c|c|c|c|c|c|}
\hline & $\begin{array}{l}\text { Sex } \\
\text { Age }\end{array}$ & Clinical features & $C T$ scan & Angiography & $\begin{array}{l}\text { EC-IC } \\
\text { bypass }\end{array}$ \\
\hline (1) & $\begin{array}{l}\text { TD } \\
\text { F } \\
60\end{array}$ & $\begin{array}{l}\text { Minor (R) hemisphere stroke ( } 1 \text { year) } \\
\text { Previous (L) carotid endarterectomy (1 year) } \\
\text { (R) hemisphere TIAs ( } 5 \text { weeks) }\end{array}$ & Normal & $\begin{array}{l}\text { (R) ICA occlusion } \\
\text { (L) CCA stenosis } \\
\text { (L) ACA occlusion }\end{array}$ & (R) \\
\hline (2) & $\begin{array}{l}\text { LS } \\
\mathbf{M} \\
51\end{array}$ & $\begin{array}{l}\text { Bilateral amaurosis fugax ( } 2 \text { years) } \\
\text { Minor (L) hemisphere stroke (18 months) } \\
\text { (L) hemisphere TIAs ( } 1 \text { year) } \\
\text { Mild dementia for } 6-12 \text { months } \\
\text { Episodes of faintness and confusion ( } 6 \text { weeks) }\end{array}$ & $\begin{array}{l}2 \text { small, ill-defined areas } \\
\text { of low attenuation in }(\mathrm{R}) \\
\text { parietal and occipital } \\
\text { watershed areas. }\end{array}$ & $\begin{array}{l}\text { (L) ICA occlusion } \\
\text { (R) ICA stenosis }(90 \%)\end{array}$ & (L) \\
\hline (3) & $\begin{array}{l}\text { QD } \\
\text { F } \\
66\end{array}$ & $\begin{array}{l}\text { (R) amaurosis fugax ( } 2 \text { years) } \\
\text { (R) hemisphere TIAs ( } 3 \text { weeks) }\end{array}$ & Normal & (R) ICA occlusion & (R) \\
\hline (4) & $\begin{array}{l}\mathrm{MD} \\
\mathbf{M} \\
70\end{array}$ & $\begin{array}{l}\text { (L) amaurosis fugax ( } 3 \text { years) } \\
\text { Minor (L) hemisphere stroke ( } 5 \text { days) } \\
\text { (L) carotid TIAs (daily) } \\
\text { Low (L) retinal artery perfusion pressure }\end{array}$ & $\begin{array}{l}\text { Small infarct in }(\mathrm{L}) \\
\text { ACA/MCA watershed } \\
\text { area }\end{array}$ & $\begin{array}{l}\text { Bilateral ICA occlusion } \\
\text { (L) ECA stenosis } \\
\text { (R) vertebral occlusion }\end{array}$ & (L) \\
\hline (5) & $\begin{array}{l}\mathrm{DH} \\
\mathrm{M} \\
56\end{array}$ & $\begin{array}{l}\text { (R) hemisphere stroke (1 year) } \\
\text { Slowly progressive dementia } \\
\text { Episodes of confusion ( } 3 \text { weeks) }\end{array}$ & $\begin{array}{l}\text { Infarcts in }(R) \text { MCA } \\
\text { territory and }(R) \\
\text { MCA/ACA watershed } \\
\text { area }\end{array}$ & (R) ICA occlusion & (R) \\
\hline (6) & $\begin{array}{l}\mathrm{HT} \\
\mathrm{M} \\
69\end{array}$ & $\begin{array}{l}\text { Minor }(\mathrm{L}) \text { hemisphere stroke }(2 \text { years) } \\
\text { Frequent orthostatic (L) hemisphere } \\
\text { TIAs ( } 2 \text { days) }\end{array}$ & $\begin{array}{l}\text { Small infarct in }(\mathrm{L}) \\
\text { internal capsule region }\end{array}$ & (L) ICA occlusion & (L) \\
\hline (7) & $\begin{array}{l}\text { EA } \\
\mathbf{M} \\
58\end{array}$ & $\begin{array}{l}\text { (L) amaurois fugax ( } 7 \text { years) } \\
\text { Minor (R) hemisphere stroke (4 years) } \\
\text { Minor (L) hemisphere stroke ( } 3 \text { weeks) }\end{array}$ & (R) fronto-parietal infarct & $\begin{array}{l}\text { (L) ICA occlusion } \\
\text { Mild (R) ICA stenosis }\end{array}$ & (L) \\
\hline (8) & $\begin{array}{l}\mathrm{KH} \\
\mathrm{M} \\
68\end{array}$ & $\begin{array}{l}\text { Minor (L) hemisphere stroke ( } 18 \text { months) } \\
\text { Frequent (L) hemisphere TIAs (daily) } \\
\text { Evolving (L) hemisphere stroke }\end{array}$ & $\begin{array}{l}\text { Small (L) frontal infarct } \\
\text { (old): No visible acute } \\
\text { infarction }\end{array}$ & Bilateral ICA occlusion & (L) \\
\hline (9) & $\begin{array}{l}\text { JS } \\
\text { M } \\
61\end{array}$ & $\begin{array}{l}\text { Personality change over } 6 \text { months } \\
\text { Mild weakness (L) leg for } 3 \text { weeks } \\
\text { Headache and mental clouding for } 1 \text { week }\end{array}$ & $\begin{array}{l}\text { Small infarct in }(\mathrm{R}) \\
\text { ACA/MCA watershed } \\
\text { area }\end{array}$ & Bilateral ICA occlusion & Bilateral \\
\hline (10) & $\begin{array}{l}\text { BO } \\
\text { M } \\
46\end{array}$ & $\begin{array}{l}\text { Orthostatic (R) hemisphere TIAs (daily) } \\
\text { (R) amaurosis fugax ( } 2 \text { weeks) } \\
\text { Low (R) retinal artery perfusion pressure }\end{array}$ & Small (R) frontal infarct & (R) ICA occlusion & (R) \\
\hline (11) & $\begin{array}{l}\text { JG } \\
\mathbf{M} \\
68\end{array}$ & $\begin{array}{l}\text { (L) amaurosis fugax ( } 2 \text { years) } \\
2 \text { syncopal episodes ( } 6 \text { months) } \\
\text { (L) retinal artery occlusion ( } 3 \text { months) } \\
\text { Orthostatic (L) hemisphere TIAs (daily) } \\
\text { Low (L) retinal artery perfusion pressure }\end{array}$ & Not done & $\begin{array}{l}\text { (L) ICA occlusion } \\
\text { (R) ECA stenosis }\end{array}$ & (L) \\
\hline (12) & $\begin{array}{l}\text { AD } \\
\mathbf{M} \\
72\end{array}$ & $\begin{array}{l}\text { Transient }(\mathrm{L}) \text { hemianopia ( } 12 \text { years) } \\
\text { Minor (L) hemisphere stroke ( } 2 \text { months) } \\
\text { (L) hemisphere TIAs ( } 2 \text { months) } \\
\text { Atypical bilateral amaurosis fugax ( } 3 \text { days) } \\
\text { Bilateral reduction of retinal artery perfusion pressure }\end{array}$ & Normal & Bilateral ICA occlusion & (L) \\
\hline
\end{tabular}

The times in brackets refer to the most recent ocurrence of each symptom prior to the pre-operative PET study. ICA, ECA, CCA, MCA and ACA refer respectively to the internal carotid, external carotid, common carotid, middle cerebral and anterior cerebral arteries.

internal carotid occlusion, further compounded in case 4 by occlusion of one vertebral artery.

The interval between the pre-operative PET study and the bypass procedure ranged from 1 day to 8 weeks (mear 5 weeks). Post-operative studies were carried out at a mean interval of 11 weeks after the procedure. Two to three months was selected as a sufficient period both to allow the bypass graft to open up fully and also to make some assessment of the patients' clinical progress. However, geographical factors and cyclotron maintenance periods dictated that two patients were studied between 1 and 2 months postoperatively and two at 5 and 6 months respectively.

Arterial blood pressure, PCV and arterial blood gases showed very little change between the times of the preoperative and follow-up studies in any of the twelve patients (table 2).

It was not the policy of any of the four surgeons involved in this study to perform post-operative angiograms on patients undergoing bypass surgery. One had specifically abandoned this practice, as others have done, ${ }^{46}$ when a patient suffered a stroke during post-operative angiography. All grafts were judged to be patent at the time of the followup PET study by the presence of palpable pulsation of the superficial temporal artery as far as the burr hole, and by Doppler ultrasound flow velocity studies confirming anterograde flow in the vessel to the limit of its extracranial course. The assessment of graft patency by Doppler examination has been well documented elsewhere ${ }^{47}$ and the technique is widely used. 17283146

\section{Results}

Clinical progress

Seven patients (cases 1, 2, 3, 5, 7, 9 and 12) had no 
Table 2 Values of arterial blood pressure, packed cell volume and arterial carbon dioxide tension (in kilopascals) at the time of the pre-operative and post-operative PET studies in each of the 12 patients (pre-operative values above)

\begin{tabular}{|c|c|c|c|}
\hline & $B P$ & $P C V$ & $\mathrm{pCO}_{2}$ \\
\hline (1) TD & $\begin{array}{l}140 / 80 \\
150 / 80\end{array}$ & $\begin{array}{l}0.42 \\
0.38\end{array}$ & $\begin{array}{l}5 \cdot 3 \\
5 \cdot 4\end{array}$ \\
\hline (2) $\mathrm{LS}$ & $\begin{array}{l}160 / 90 \\
160 / 100\end{array}$ & $\begin{array}{l}0.42 \\
0.38\end{array}$ & $\begin{array}{l}5 \cdot 5 \\
5 \cdot 1\end{array}$ \\
\hline (3) $\mathrm{QS}$ & $\begin{array}{l}140 / 80 \\
150 / 80\end{array}$ & $\begin{array}{l}0.36 \\
0.41\end{array}$ & $\begin{array}{l}4.9 \\
5 \cdot 3\end{array}$ \\
\hline (4) MD & $\begin{array}{l}145 / 90 \\
150 / 90\end{array}$ & $\begin{array}{l}0.29 \\
0.39\end{array}$ & $\begin{array}{l}5 \cdot 1 \\
5 \cdot 0\end{array}$ \\
\hline (5) $\mathrm{DH}$ & $\begin{array}{l}140 / 75 \\
120 / 70\end{array}$ & $\begin{array}{l}0.37 \\
0.39\end{array}$ & $\begin{array}{l}6 \cdot 1 \\
5.9\end{array}$ \\
\hline (6) $\mathrm{HT}$ & $\begin{array}{l}140 / 80 \\
140 / 80\end{array}$ & $\begin{array}{l}0.42 \\
0.40\end{array}$ & $\begin{array}{l}4 \cdot 9 \\
5 \cdot 2\end{array}$ \\
\hline (7) $\mathrm{EA}$ & $\begin{array}{l}140 / 80 \\
140 / 90\end{array}$ & $\begin{array}{l}0.42 \\
0.49\end{array}$ & $\begin{array}{l}5 \cdot 6 \\
5 \cdot 3\end{array}$ \\
\hline (8) $\mathrm{KH}$ & $\begin{array}{l}150 / 85 \\
160 / 80\end{array}$ & $\begin{array}{l}0.38 \\
0.44\end{array}$ & $\begin{array}{l}4 \cdot 5 \\
5 \cdot 5\end{array}$ \\
\hline (9) JS & $\begin{array}{l}140 / 85 \\
150 / 85\end{array}$ & $\begin{array}{l}0.45 \\
0.38\end{array}$ & $\begin{array}{l}5 \cdot 2 \\
5 \cdot 2\end{array}$ \\
\hline (10) BO & $\begin{array}{l}155 / 95 \\
150 / 100\end{array}$ & $\begin{array}{l}0.38 \\
0.38\end{array}$ & $\begin{array}{l}5 \cdot 6 \\
5 \cdot 4\end{array}$ \\
\hline (11) JG & $\begin{array}{l}170 / 90 \\
190 / 90\end{array}$ & $\begin{array}{l}0.36 \\
0.37\end{array}$ & $\begin{array}{l}4 \cdot 4 \\
4 \cdot 7\end{array}$ \\
\hline (12) AD & $\begin{array}{l}190 / 90 \\
160 / 80\end{array}$ & $\begin{array}{l}0.39 \\
0.35\end{array}$ & $\begin{array}{l}5 \cdot 3 \\
5 \cdot 4\end{array}$ \\
\hline
\end{tabular}

further acute symptoms during a mean interval of 11 weeks between the time of surgery and their follow-up PET study. Little significance could be attached to this, however, since these patients had all presented with either an isolated minor stroke or relatively infrequent TIAs. One patient (case 3) reported postoperative improvement of the power in her left leg, but this had not been objectively weak prior to surgery, even after a prolonged period of walking. The other six patients in this group noted no improvement in any existing neurological deficit and their physical signs were unchanged.

Of more interest were the three patients with frequent, posturally related TIAs prior to surgery. One of these (case 6) had only one further hemiparetic episode during the early post-operative period, after which his attacks stopped completely. The other two (cases 10 and 12) reported a few further episodes but with markedly diminished frequency during the weeks leading up to their follow-up studies.

Also of particular interest were the two patients, both with bilateral carotid occlusion, whose original clinical features had suggested a state of critically reduced cerebral perfusion. Patient 4 , who presented with daily TIAs and a minor watershed infarct in the left hemisphere, woke up after the bypass operation with dysphasia and a dense right hemiparesis. There was some improvement of this deficit over the ensuing weeks and he had no further TIAs. Patient 8 , who had a history of increasingly frequent TIAs and an evolving cerebral infarct at the time of surgery, showed no
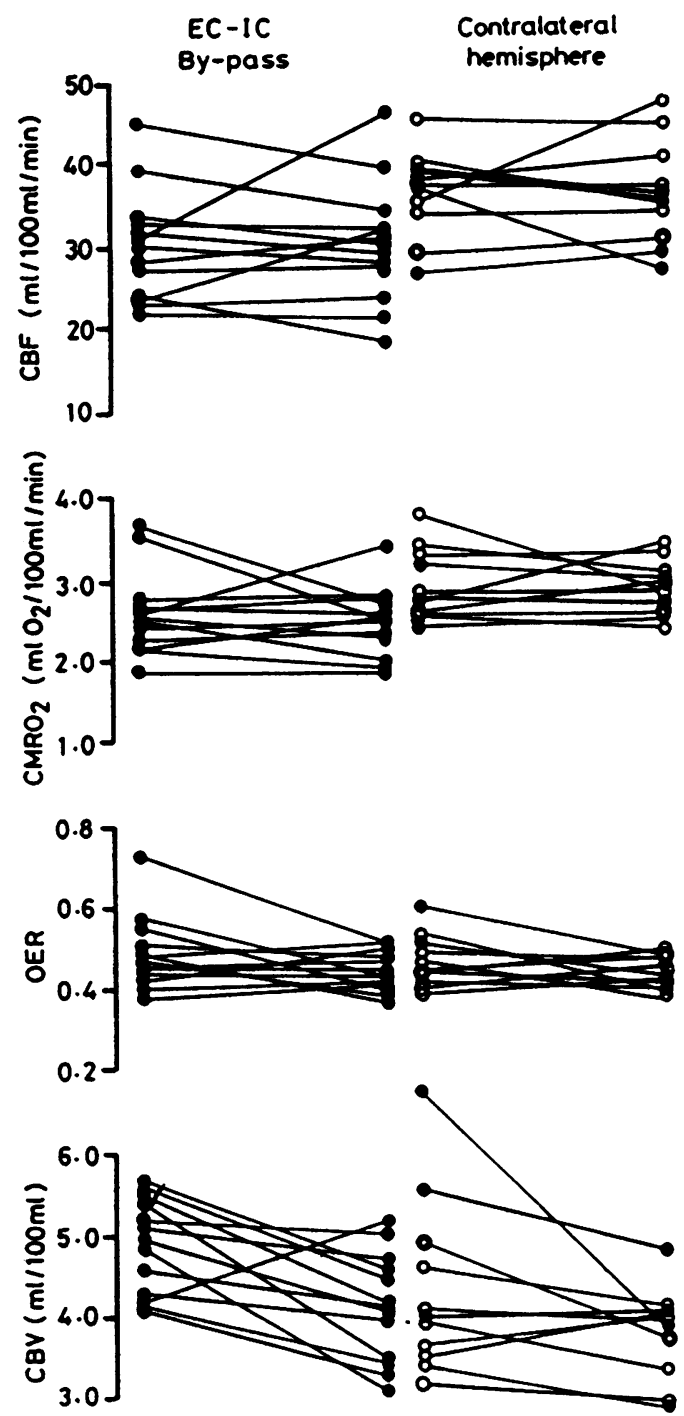

Fig 2 Individual values of $\mathrm{CBF}, \mathrm{CMRO}_{2}, \mathrm{OER}$ and $\mathrm{CBV}$ before and after bypass surgery in the "cortical" $M C A$ territories (pre-operative values on the left of each pair). Regions distal to occluded carotid arteries are represented by closed circles, patent arteries by open circles, and the severely stenosed contralateral vessel in case 2 by an intermediate symbol.

further deterioration and made a slow partial recovery from his hemiparesis and dysphasia during the months following the bypass procedure.

\section{Physiological findings}

Values of cerebral blood flow (CBF), oxygen utilisation $\left(\mathrm{CMRO}_{2}\right)$, fractional oxygen extraction (OER) and blood volume (CBV) within the cortical MCA 


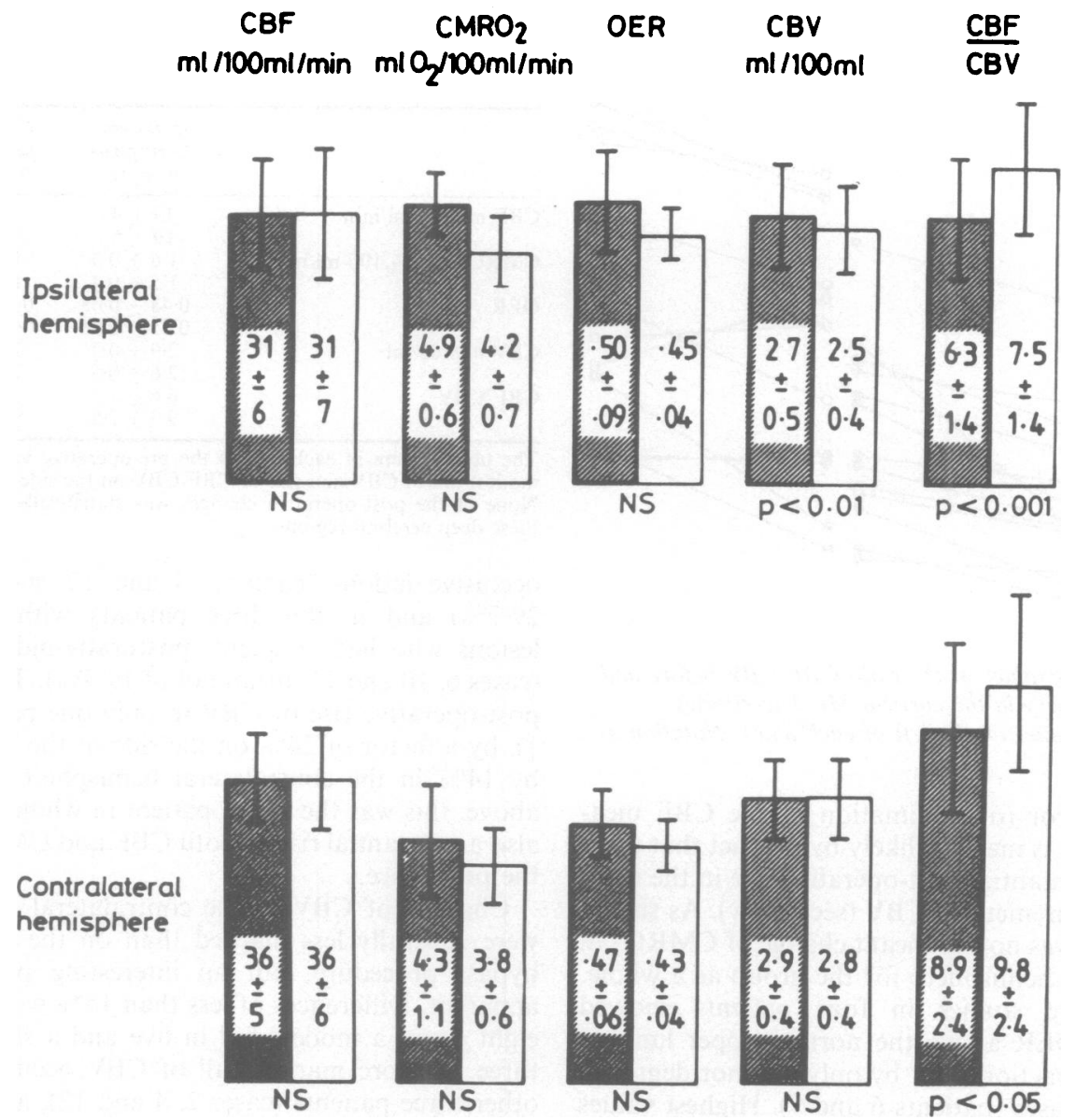

Fig 3 Mean values in the cortical MCA territories before (left hand columns) and after bypass surgery in the ipsilateral and contralateral cerebral hemispheres. Statistical comparisons by paired $t$ test.

regions before and after surgery are shown in fig 2 . Since one patient (case 9) had bilateral EC-IC bypass procedures, there were thirteen "operated" hemispheres and eleven in the contralateral category. For the statistical comparisons between pre- and postoperative findings on the operated side, only the values from the symptomatic (right) hemisphere were included from the patient who had bilateral surgery. This was because data from both cerebral hemispheres in a single patient could not be regarded as two independent measurements.

Cerebral blood flow rose post-operatively by more than $10 \%$ in only two of the twelve patients, by $44 \%$ in case 1 and by $33 \%$ in case 9 , the patient who had bilateral surgery. Amongst the other ten patients there was a fall of CBF in three (by $11 \%, 21 \%$ and $12 \%$ in cases, 3, 4 and 12 respectively) and no appreciable change in the remaining seven. Mean CBF in the group as a whole showed no change in either cerebral hemisphere (fig 3).

Regional $\mathrm{CMRO}_{2}$ rose post-operatively in only two patients: in case 2 , by a factor of $31 \%$ on the side of the bypass and $26 \%$ in the contralateral hemisphere, and in case 11 by $18 \%$ and $11 \%$ respectively on the operated and contralateral sides. There was no change of $\mathrm{CMRO}_{2}$ in seven cases and a fall in three; those with a fall in oxygen consumption included patient 4 , who sustained the peri-operative cerebral infarct, and patient 8 , who was already in the throes of a stroke at the time of surgery. The rise of $\mathrm{CMRO}_{2}$ in patient 1 was observed in both cerebral hemispheres but was more marked on the side of the bypass. This apparent enhancement of cerebral function was not associated with any detectable alteration in the patient's clinical state. Although the recorded rise of both CBF and $\mathrm{CMRO}_{2}$ in this case could possibly have resulted from 


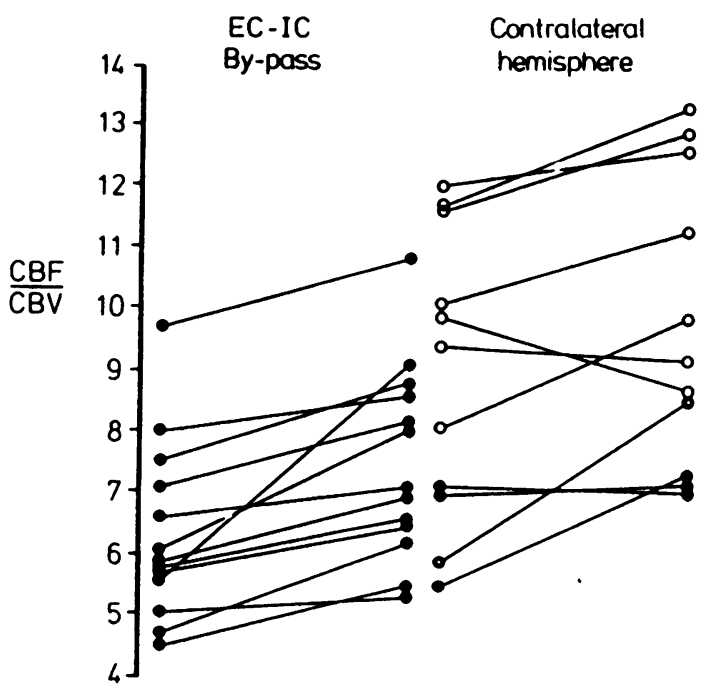

Fig 4 Individual values of the ratio $C B F / C B V$ before and after bypass surgery in the cortical MCA territories (pre-operative values on the left of each pair). Notation as in fig 2.

a technical error (overestimation of the CBF measurement), this is made unlikely by the fact that there was also a substantial post-operative rise in the independent measurement of CBV (see below). As shown in fig 3, there was no significant change of $\mathrm{CMRO}_{2}$ in either cerebral hemisphere for the group as a whole.

Pre-operative studies in four patients showed elevation of OER above the normal upper limit of 0.50 ( $50 \%$ extraction), but by only a minor degree in two of these cases (patients 6 and 9). Highest values were observed in the two patients with very frequent TIAs in association with bilateral carotid occlusion (OER of 0.73 in case 4 and 0.57 in case 8 ). There was a post-operative fall of OER to normal levels in all four cases with high pre-operative values, but in only one of these (case 9) was this due to increased cerebral blood flow. In the other three there had simply been a fall of cerebral oxygen demand $\left(\mathrm{CMRO}_{2}\right)$, which in the two most critical cases was accompanied by clinical evidence of cerebral infarction. In the remaining eight cases there was little post-operative change of OER in either cerebral hemisphere. The slight fall of mean OER in the group as a whole was not statistically significant (fig 3 ).

The most consistent physiological change after bypass surgery was observed in the cerebral blood volume, which showed a fall on the side of the procedure in eleven of the twelve patients (fig 2). The change of CBV was very small in three of these cases (4-9\%) but ranged from $16 \%$ to $36 \%$ in the other eight patients. The most marked reductions of CBV were observed in three patients with bilateral
Table 3 Mean $( \pm S D)$ subcortical values of $C B F$, $\mathrm{CMRO}_{2}, \mathrm{OER}, \mathrm{CBV}$ and $\mathrm{CBF} / \mathrm{CBV}$ before and after bypass surgery in the 12 patients

\begin{tabular}{lcc}
\hline & $\begin{array}{l}\text { Ipsilateral } \\
\text { hemisphere } \\
(n=13)\end{array}$ & $\begin{array}{l}\text { Contralateral } \\
\text { hemisphere } \\
(n=11)\end{array}$ \\
\hline $\mathrm{CBF} \mathrm{ml} / 100 \mathrm{ml} / \mathrm{min}$ & $19 \pm 4$ & $23 \pm 5$ \\
& $19 \pm 5$ & $23 \pm 2$ \\
$\mathrm{CMRO}_{2} \mathrm{ml} \mathrm{O}_{2} / 100 \mathrm{ml} / \mathrm{min}$ & $1.6 \pm 0.3$ & $1.8 \pm 0.4$ \\
& $1.5 \pm 0.4$ & $1.7 \pm 0.2$ \\
OER & $0.48 \pm 0.08$ & $0.43 \pm 0.06$ \\
$\mathrm{CBV} \mathrm{ml} / 100 \mathrm{ml}$ & $0.45 \pm 0.06$ & $0.41 \pm 0.06$ \\
$\mathrm{CBF} / \mathrm{CBV}$ & $2.9 \pm 0.7$ & $2.8 \pm 1.1$ \\
& $2.6 \pm 0.5$ & $2.6 \pm 0.2$ \\
& $6.6 \pm 1.5$ & $7.2 \pm 2.2$ \\
\hline
\end{tabular}

The upper figure in each case is the pre-operative value. Note the modest fall of $\mathrm{CBV}$ and rise of $\mathrm{CBF} / \mathrm{CBV}$ on the side of the bypass. None of the post-operative changes was statistically significant in these deep cerebral regions.

occlusive lesions (cases 2, 4 and 12, mean fall of $29.7 \%$ ) and in the three patients with unilateral lesions who had frequent, posturally-induced TIAs (cases 6, 10 and 11, mean fall of $19.7 \%$ ). There was a post-operative rise of CBV in only one patient (case 1), by a factor of $24 \%$ on the side of the bypass and by $14 \%$ in the contralateral hemisphere. As noted above, this was the single patient in whom there was also a substantial rise of both $\mathrm{CBF}$ and $\mathrm{CMRO}_{2}$ after the procedure.

Changes of CBV in the contralateral hemisphere were generally less marked than on the side of the bypass procedure, but an interesting pattern was apparent. Differences of less than $15 \%$ were noted in eight cases, a modest fall in five and a slight rise in three. A more marked fall of CBV occurred in the other three patients (cases 2, 4 and 12), all of whom had had substantially elevated CBV in both hemispheres on their pre-operative studies (fig 2). Two of these patients had complete bilateral carotid occlusion and the third (case 2) had severe carotid stenosis on one side and complete occlusion on the other. In the group as a whole there was a mean post-operative fall of CBV in both cerebral hemispheres, which on the operated side was statistically significant $(p<0.01$, see fig 3).

The changes of $\mathrm{CBF}$ and $\mathrm{CBV}$ after surgery were such that the ratio $\mathrm{CBF} / \mathrm{CBV}$ rose post-operatively in all thirteen of the operated hemispheres $(p<0.001$, fig 3 ) and in seven of the eleven contralateral hemispheres $(p<0.05)$. The individual pre- and postoperative values of CBF/CBV are illustrated in fig 4.

Values of the four variables and the $C B F / C B V$ ratio from the subcortical cerebral regions are summarised in table 3. In general, the post-operative changes ran in parallel with those in the superficial MCA regions but were less marked. Again the most consistent trend was observed in the CBV values, which fell after surgery in ten of the thirteen operated hemispheres. 
However, the degree of change in these deeper cerebral regions was relatively small and did not achieve statistical significance for the group as a whole. As in the cortical regions, mean $\mathrm{CBF}$ and $\mathrm{CMRO}_{2}$ remained unchanged, and a slight reduction of mean OER was accounted for by moderate falls in a few patients with raised pre-operative values (cases 4, 6 and 8).

\section{Discussion}

In accordance with the findings in several previous studies, ${ }^{162332}$ only a small minority of the patients presented here showed an increase of cerebral blood flow after EC-IC bypass surgery. This was not unexpected, however, since pre-operative blood flow in the majority of cases was appropriate for cerebral metabolic demands (CBF matched to $\mathrm{CMRO}_{2}, \mathrm{OER}$ normal). In this situation less than half of the oxygen delivered to the brain is being extracted and metabolised. Any increase of blood flow would therefore be superfluous unless there was a concomitant rise of cerebral oxygen demand. Since pre-operative metabolic activity was not constrained by a lack of oxygen supply, and blood flow is normally coupled closely to metabolic demand, ${ }^{34}{ }^{36}$ neither $\mathrm{CMRO}_{2}$ nor CBF would be expected to rise in response to improved collateral blood supply. The finding in many preoperative studies of a modest, matched reduction of CBF and $\mathrm{CMRO}_{2}$, with less than $50 \%$ of available oxygen being extracted, implied that a minor degree of irreversible ischaemic damage had occurred in these patients. ${ }^{36}$ Consistent with this interpretation was the fact that $\mathrm{CMRO}_{2}$ remained unchanged (or actually fell) after surgery in eleven of the twelve patients. The exception to this was the single patient (case 1) in whom there was a matched increase of both $\mathrm{CMRO}_{2}$ and CBF at the time of the follow-up study. An associated rise of $C B V$ suggested that this was a genuine physiological change rather than a technical error, for example in the CBF measurement. Since the preoperative values were not unduly low and OER was normal, it is difficult to attribute the metabolic change in this patient to an effect of surgical revascularisation. A similar degree of variation in both $\mathrm{CMRO}_{2}$ and $\mathrm{CBF}$ is occasionally seen in normal subjects studied serially. ${ }^{163442}$ Although one recent study has shown substantial increases of $\mathrm{CMRO}_{2}$ after bypass surgery, ${ }^{48}$ this unexpected finding has not been observed by others. ${ }^{1649}$

The finding of normal fractional oxygen extraction implies that cerebral perfusion pressure remains within the range of effective autoregulation, since blood flow is still appropriately matched to cerebral oxygen requirements. ${ }^{36} 37$ When CBF becomes inappropriately low in relation to $\mathrm{CMRO}_{2}$, it can be assumed that local perfusion pressure has fallen below the autoregulatory range, at which point oxygen delivery to the tissues is maintained by a compensatory rise of OER. ${ }^{36}$ This critical situation has been shown to be reversible by successful EC-IC bypass surgery, ${ }^{1625}$ as was the case in one of our patients (case 9). However, the two patients in our series who were most in need of increased blood flow both developed cerebral infarction, one during the immediate pre-operative period (case 8) and the other at the time of surgery (case 4). The occurrence of a peri-operative stroke in the latter case highlights a clinical dilemma which also arises in relation to carotid endarterectomy: those patients with most to gain from surgery are also likely to carry the highest operative risk. Others have also observed that early postoperative ischaemic events occur most often in patients with unstable neurological symptoms prior to bypass surgery, and that these episodes may sometimes be attributable to variations of arterial blood pressure. ${ }^{46} \mathrm{~A}$ more unusual complication in patients with critically reduced cerebral perfusion pressure is the development of reperfusion haemorrhage after bypass surgery. ${ }^{46} 5051$

The most striking observation in this study was the post-operative fall of cerebral blood volume in almost every case. Interpretation of CBV changes is not straightforward, since a large proportion of the blood volume compartment is made up by the venous side of the circulation. Nevertheless, experimental studies have shown that the CBV tends to rise as perfusion pressure falls, ${ }^{5253}$ and several clinical studies have demonstrated focal elevation of CBV in the presence of occlusive vascular lesions. ${ }^{363754}$ Although this phenomenon may be partly attributed to compensatory vasodilatation in arteriolar resistance vessels as perfusion pressure falls, ${ }^{36375255}$ this is unlikely to be the sole explanation. ${ }^{36}$ Additional factors may include an associated dilatation of superficial cerebral veins, which has been shown experimentally, and some degree of capillary dilatation or recruitment. Also, when blood volume is measured with a red cell tracer, as in this study, the relatively small change of CBV due to arteriolar dilatation may be somewhat amplified as a result of an associated rise in cerebral haematocrit within the region of vasodilatation. ${ }^{5960}$

In a previous study of patients with carotid artery disease, the degree of elevation of CBV was found to correlate with the extent of occlusive disease as judged by angiography. ${ }^{36}$ This is consistent with the finding that direct measurements of cerebral perfusion pressure show substantially lower values in patients with bilateral carotid occlusion than in those with unilateral lesions. ${ }^{19}$ The fall of previously elevated regional CBV after bypass surgery suggests that although blood flow remained unchanged in most of 
these patients, the procedure had produced a rise of local cerebral perfusion pressure. It was of interest in this respect that the most marked post-operative falls of CBV occurred in patients with bilateral carotid occlusion and in those with posturally induced TIAs. In three patients with bilateral occlusive disease there was also a substantial fall of CBV in the contralateral hemisphere, consistent with improvement of collateral reserve in both carotid territories. Similar bilateral changes have been observed within a few days of surgery in patients undergoing endarterectomy of a severely stenosed carotid artery in the presence of a contralateral occlusion (Gibbs et al, unpublished observations).

For reasons discussed previously, ${ }^{36}$ the ratio of $\mathrm{CBF} / \mathrm{CBV}$ is likely to provide a more reliable index of prevailing perfusion pressure than either CBF or CBV taken alone. Consideration of this ratio was to some extent superfluous for comparison of the serial studies presented here, since the trend in almost all patients consisted of a fall of CBV without any change of CBF. Nevertheless, it was of interest that the CBF/CBV ratio rose after surgery in every single case, including the patient in whom there was a post-operative rise of CBV. Also, an increase of CBF/CBV was the only statistically significant change observed in the hemisphere contralateral to the bypass $(p<0.05$, fig 3 ). This supports the view that combined analysis of blood flow and blood volume may be a useful approach when studying patients with less elaborate techniques than PET. ${ }^{36}$

A state of reduced circulatory reserve (compensatory vasodilatation in the face of reduced perfusion pressure) can also be demonstrated in patients with carotid occlusion as impairment of the capacity to increase $\mathrm{CBF}$ in response to inhaled carbon dioxide. ${ }^{33}$ The degree of impairment of $\mathrm{CO}_{2}$ reactivity is more marked in patients with bilateral carotid occlusion ${ }^{59}$ and in those with unilateral lesions who have angiographic evidence of poor collateral supply from the contralateral carotid system. ${ }^{33}$ Furthermore, the most striking change after bypass surgery may be a return towards normal of the $\mathrm{CO}_{2}$ reactivity with little or no alteration of CBF itself. ${ }^{26}$ This latter finding is clearly analogous to the post-operative fall of cerebral blood volume observed in our cases. Other investigators have noted raised CBV in patients with carotid artery occlusion, although only a proportion of cases showed a fall of blood volume after EC-IC bypass surgery. ${ }^{16}$ In the study in question, however, use of the entire cerebral hemisphere as a region of analysis was liable to overlook more subtle post-operative changes in the territory of the bypassed carotid vessel. In addition, quotation of results as hemispheric ratios, rather than as absolute values of $\mathrm{CBV}$, would underestimate or overlook completely a more widespread post-operative change which also affected the contralateral hemisphere. Although a modest fall of CBV was observed in the deep subcortical regions in this study, the more substantial change in the superficial MCA territories indicated that the vessels undergoing a change of calibre were largely those in the cortical grey matter or over the surface of the brain. This is consistent with existing knowledge about the vessels responsible for cerebral autoregulation. 556061

It is not possible to draw any conclusions about the clinical efficacy of bypass surgery from the study of twelve patients. The only notable trend was observed in the three patients with orthostatic hemispheric TIAs (cases 6, 10 and 11), all of whom reported cessation or marked reduction in the frequency of their attacks in the weeks following surgery. This symptomatic improvement in the early post-operative period suggests that the striking fall of CBV in these patients was due to the bypass procedure itself, rather than to spontaneous improvement of collateral supply. However, this issue could only be clarified with certainty by serial studies in a comparable group of patients who were not subjected to surgery.

The main points emerging from this study can be summarised as follows. Haemodynamic measurements confim that in some patients with occlusive carotid artery disease, there is evidence of critically reduced cerebral perfusion pressure. This situation arises most often in patients with bilateral occlusive lesions, and is usually associated with characteristic clinical features of a critical haemodynamic state. Cerebral blood flow is rarely increased after EC-IC bypass surgery but a post-operative fall of cerebral blood volume is consistent with improvement of cerebral perfusion pressure as a result of the procedure. Measurement of regional $\mathrm{CO}_{2}$ reactivity should be an equally satisfactory method for assessment of cerebral circulatory reserve. Although the greatest haemodynamic improvement after bypass surgery is observed in patients with most abnormal preoperative findings, those same patients are also likely to have the highest risk of peri-operative cerebral infarction. The disappointingly high incidence of operative stroke reported by the International Study ${ }^{22}$ would certainly be consistent with this view.

We thank Professor RM Greenhalgh, Professor J Lumley and $\mathrm{Mr} \mathrm{K}$ Burnand, who performed some of the bypass operations and allowed their patients to be studied; Professor L Symon and Dr M O'Brien for referring additional cases; Dr RSJ Frackowiak and Dr Terry Jones for helpful advice and discussion; all the staff of the MRC Cyclotron Unit, in particular Miss Rowie Jackson for preparing the manuscript. 
References

1 Dyken ML, Pokras R. The performance of endarterectomy for disease of the extracranial arteries of the head. Stroke 1984;15:948-50.

2 Warlow CP. Carotid endarterectomy: does it work? Stroke 1984;15:1068-76.

3 Donaghy PMP. Patch and bypass in mircoangeional surgery. In: Donaghy PMP, Yasargil MG, eds. MicroVascular Surgery. St Louis: CV Mosby Company, 1967:75-86.

4 Yasargil MG, Krayenbuhl HA, Jacobson JH. Microneurosurgial arterial reconstruction. Surgery 1970;67: 221-33.

5 McDowell FH, Potes J, Groch S. The natural history of internal carotid and vertebrobasilar occlusion. Neurology 1961;11:153-7.

6 Hardy WG, Lindner DW, Thomas LM, Gurdjian EJ. Anticipated course in carotid artery occlusion. Arch Neurol 1962;6:138-50.

7 Marshall J. The management of occlusion and stenosis of the internal carotid artery. Neurology 1966;16: 1087-93.

8 Dyken, ML, Klatte E, Kolar OJ, Spurgeon C. Complete occlusion of common or internal carotid arteries: clinical significance. Arch Neurol 1974;30:343-6.

9 Grillo P, Patterson RH. Occlusion of the carotid artery: prognosis (natural history) and the possibilities of surgical revascularisation. Stroke 1975;6:17-20.

10 Fields WS, Lemak NA. Joint study of extracranial arterial occlusion $\mathrm{X}$. Internal carotid artery occlusion. JAMA 1976;235:2734-8.

11 Furlan AJ, Whisnant JP, Baker HL. Long term prognosis after carotid artery occlusion. Neurology 1980;30: 986-8.

12 Harrison MJG, Marshall J. Prognostic significance of severity of carotid atheroma in early manifestations of cerebrovascular disease. Stroke 1982;13:567-9.

13 Cote R, Barnett HJM, Taylor DW. Internal carotid occlusion: a prospective study. Stroke 1983;14: 898-902.

14 Barnett HJM. Is there a place for cerebral revascularisation? Clin Neurosurg 1979;26:314-29.

15 Marshall J. Indications for extracranial-intracranial anastomosis. In: Rice Edwards JM, ed. Topical Reviews in Neurosurgery VI. Bristol: John Wright and Sons, 1982:81-92.

16 Powers WJ, Martin WRW, Herscovitch P, Raichle ME, Grubb RL. Extracranial-intracranial bypass surgery: haemodynamic and metabolic effects. Neurology 1984;34:1168-74.

17 Jaques S, Garner J. Reversal of aphasia with superficial temporal to middle cerebral artery anastomosis. Surg Neurol 1976;5:143-5.

18 Roski R, Spetzler RF, Owen M, Chandar K, Sholl JG, Nulsen FE. Reversal of seven year old visual field defect with extracranial-intracranial arterial anastomosis. Surg Neurol 1978;10:267-8.

19 Spetzler RF, Roski RA, Zabramski J. Middle cerebral artery pressure in cerebrovascular occlusive disease. Stroke 1983;14:552-5.

20 Whisnant JP, Sundt TM, Fode NC. Long-term mortality and stroke morbidity after superficial temporal artery-middle cerebral artery bypass operation. Mayo Clin Proc 1985;60:241-6.

21 The EC-IC Bypass Study Group. The International Cooperative Study of Extracranial-Intracranial Arterial Anastomosis: methodology and entry characteristics. Stroke 1985;16:397-406.

22 The EC/IC Bypass Study Group. Failure of extracranialintracranial bypass to reduce the risk of ischaemic stroke: results of an international randomised trial. $N$ Engl J Med 1985;313:1191-200.

23 Austin G, Laffin D, Hayward W. Physiologic factors in the selection of patients for superficial temporal arteryto-middle cerebral artery anastomosis. Surgery 1974;75:961-8.

24 Schmiedek P, Gratzl O, Spetzler R, Steinhoff H, Enzenbach R, Brendel W, Marguth F. Selection of patients for extra-intracranial arterial bypass surgery based on rCBF measurements. $J$ Neurosurg 1976;44: 303-12.

25 Baron JD, Bousser MG, Rey A, Guillard A, Comar D, Castaigne P. Reversal of "misery perfusion syndrome" by extra-intracranial arterial bypass in haemodynamic cerebral ischaemia. Stroke 1981;12:454-9.

26 Halsey JH, Morawetz RB, Blauenstein UW. The haemodynamic effect of STA/MCA bypass. Stroke 1982;13:163-7.

27 Meyer JS, Nakajima S, Okabe T, et al. Redistribution of cerebral blood flow following STA-MCA bypass in patients with hemispheric ischaemia. Stroke 1982;13: 774-84.

28 de Weerd AW, Veering MM, Mosmans PCM, van Huffelen AC, Tulleken CAF, Jonkman EJ. Effect of the extracranial-intracranial arterial anastomosis on EEG and cerebral blood flow: a controlled study of patients with unilateral cerebral ischaemia. Stroke 1982;13:674-9.

29 Veering MM, Mosmans PCM, de Weerd AW, Jonkman EJ. Effect of STA-MCA anastomosis (EC-IC bypass) and carotid endarterectomy on rCBF. J Cereb Blood Flow Metabol 1983;3:S604-5.

30 Awad I, Little JR, Bryerton B, Furlan AJ. Regional cerebral blood flow in extracranial-intracranial bypass surgery. J Cereb Blood Flow Metabol 1983;3:S596-7.

31 Tsuda Y, Kimura K, Iwata Y, et al. Improvement of cerebral blood flow and/or $\mathrm{CO}_{2}$ reactivity after superficial temporal artery-middle cerebral artery bypass in patients with transient ischaemic attacks and watershed zone infarctions. Surg Neurol 1984;22: 595-604.

32 Tanahashi N, Meyer JS, Rogers RL, et al. Long term assessment of cerebral perfusion following STA-MCA bypass in patients. Stroke 1985;16:85-91.

33 Norrving B, Nilsson B, Risberg J. rCBF in patients with carotid occlusion: resting and hypercapnic flow related to collateral pattern. Stroke 1982;13:155-62.

34 Frackowiak RSJ, Lenzi GL, Jones T, Heather JD. Quantitative measurement of cerebral blood flow and oxygen metabolism in man using ${ }^{15} \mathrm{O}$ and positron emission tomography: Theory, procedure and normal values. J Comput Assist Tomogr 1980;4:727-36.

35 Phelps ME, Mazziotta JC, Huang SC. Study of cerebral 
function with positron computed tomography. J Cereb Blood Flow Metabol 1982;2:113-62.

36 Gibbs JM, Wise RJS, Leenders KL, Jones T. Evaluation of cerebral perfusion reserve in patients with carotid artery occlusion. Lancet 1984;1:310-14.

37 Powers WJ, Grubb RL, Raichle ME. Physiological responses to focal cerebral ischaemia in humans. Ann Neurol 1984;16:546-52.

38 Gibbs JM, Wise RJS, Leenders KL, Herold S, Frackowiak RSJ, Jones T. Cerebral haemodynamics in occlusive carotid-artery disease. Lancet 1985;1:933-4.

39 Phelps ME, Hoffman EJ, Huang SC, Kuhl DE. ECAT: A new computerised tomographic imaging system for positron-emitting radiopharmaceuticals. J Nucl $\mathrm{Med}$ 1978;20:328-34.

40 Phelps ME, Huang S-C, Hoffman EJ, Kuhl DE. Validation of tomographic measurement of cerebral blood volume with C-11 labelled carboxyhaemoglobin. J Nucl Med 1979;20:328-34.

41 Lammertsma AA, Jones T. Correction for the presence of intravascular oxygen-15 in the steady-state technique for measuring regional oxygen extraction ratio in the brain: 1. Description of the method. $J$ Cereb Blood Flow Metabol 1983;3:416-24.

42 Frackowiak RSJ. Human regional cerebral blood flow and oxygen metabolism studied with oxygen-15 and positron emission tomography. MD Thesis, University of Cambridge, 1982.

43 Wise RJS, Bernardi S, Frackowiak RSJ, Legg NJ, Jones $T$. Serial observations on the pathophysiology of acute stroke: the transition from ischaemia to infarction as reflected in regional oxygen extraction. Brain 1983;106: 197-222.

44 Kearns TP, Hollenhorst RW. Venous stasis retinopathy of occlusive disease of the carotid artery. Mayo Clin Proc 1963;38:304-12.

45 Ross Russell RWR, Page NGR. Critical perfusion of brain and retina. Brain 1983;106:419-34.

46 Sundt TM, Whisnant JP, Fode NC, Piepgras TG, Houser DW. Results, complications and follow-up of 415 bypass operations for occlusive disease of the carotid system. Mayo Clin Proc 1985;60:230-40.

47 Tanaka K, Nukada T, Yoneda S, Kimura K, Abe H, Iwata $Y$. Ultrasonic evaluation of superficial temporal-artery-middle cerebral artery anastomosis. Stroke 1981;12:803-7.
48 Samson Y, Baron JC, Bousser MG, et al. Effects of extraintracranial arterial bypass on cerebral blood flow and oxygen metabolism in humans. Stroke 1985;16: 609-16.

49 Martin WRW, Raichle ME. Cerebellar blood flow and metabolism in cerebral hemisphere infarction. Ann Neurol 1983;14:168-76.

50 Heros RC, Nelson PB. Intracerebral haemorrhage after microsurgical cerebral revascularisation. Neurosurgery 1980;6:371-5.

51 Sundt TM, Siekert RG, Piepgras RG, Sharbrough FW, Houser DW. Bypass surgery for vascular disease of the carotid system. Mayo Clin Proc 1976;51:677-92.

52 Grubb RL, Phelps ME, Raichle ME. The effects of arterial blood pressure on the regional cerebral blood volume by X-ray fluorescence. Stroke 1973;4:390-9.

53 Grubb RL, Raichle ME, Phelps ME. Effects of increased intracranial pressure on cerebral blood volume, blood flow and oxygen metabolism in monkeys. $J$ Neurosurg 1975;43:385-98.

54 Grubb RL, Raichle ME, Eichling JO, Gado MH. Effects of subarachnoid haemorrhage on cerebral blood volume, blood flow and oxygen utilisation in humans. J Neurosurg 1977;46:446-53.

55 Kontos HA. Regulation of cerebral circulation. Ann Rev Physiol 1981;43:397-407.

56 Weiss HR, Buchweitz EL, Murtha TJ, Auletta M. Quantitative regional determination of morphometric indices of the total and perfused capillary network in the rat brain. Circ Res 1982;51:494-503.

57 Larsen OA, Lassen N. Cerebral haematocrit in normal man. J Appl Physiol 1964;19:571-4.

58 Lammertsma AA, Brooks DJ, Beaney RP, et al. In vivo measurement of regional cerebral haematocrit using positron emission tomography. J Cereb Blood Flow Metabol 1984;4:317-22.

59 Brown MM, Wade JPH, Bishop CCR, Ross Russell RW. Reactivity of the cerebral circulation in patients with carotid occlusion. J Neurol Neurosurg Psychiatry 1986;49:899-904.

60 Fog M. The relationship between the blood pressure and the tonic regulation of the pial arteries. $J$ Neurol Psych 1938;1:187-97.

61 Meyer JS, Denny-Brown D. The cerebral collateral circulation: I. Factors influencing collateral blood flow. Neurology 1957;7:447-58. 